ARTICLE

https://doi.org/10.1038/s41467-019-11789-3

\title{
Quadruple perovskite ruthenate as a highly efficient catalyst for acidic water oxidation
}

\author{
Xianbing Miao ${ }^{1,3}$, Lifu Zhang ${ }^{2,3}$, Liang Wu${ }^{1}$, Zhenpeng Hu ${ }^{2}{ }^{2}$, Lei Shi ${ }^{1} \&$ Shiming Zhou ${ }^{1}$
}

Development of highly active and durable oxygen-evolving catalysts in acid media is a major challenge to design proton exchange membrane water electrolysis for producing hydrogen. Here, we report a quadruple perovskite oxide $\mathrm{CaCu}_{3} \mathrm{Ru}_{4} \mathrm{O}_{12}$ as a superior catalyst for acidic water oxidation. This complex oxide exhibits an ultrasmall overpotential of $171 \mathrm{mV}$ at $10 \mathrm{~mA}$ $\mathrm{cm}^{-2}$ geo, which is much lower than that of the state-of-the-art $\mathrm{RuO}_{2}$. Moreover, compared to $\mathrm{RuO}_{2}, \mathrm{CaCu}_{3} \mathrm{Ru}_{4} \mathrm{O}_{12}$ shows a significant increase in mass activity by more than two orders of magnitude and much better stability. Density functional theory calculations reveal that the quadruple perovskite catalyst has a lower $\mathrm{Ru} 4 \mathrm{~d}$-band center relative to $\mathrm{RuO}_{2}$, which effectively optimizes the binding energy of oxygen intermediates and thereby enhances the catalytic activity.

\footnotetext{
${ }^{1}$ Hefei National Laboratory for Physics Sciences at the Microscale, University of Science and Technology of China, Hefei, Anhui 230026, P. R. China. ${ }^{2}$ School of Physics, Nankai University, Tianjin 300071, P. R. China. ${ }^{3}$ These authors contributed equally: Xianbing Miao, Lifu Zhang. Correspondence and requests for materials should be addressed to Z.H. (email: zphu@nankai.edu.cn) or to S.Z. (email: zhousm@ustc.edu.cn)
} 
P roton exchange membrane water electrolysis (PEMWE) has sparked widely attention as a most promising technology for direct conversion of electrical energy into fuels by electrochemical water splitting ${ }^{1-3}$. Essential to the water electrolyzers is oxygen evolution reaction (OER) taking place at anode, where a complex multistep proton-coupled electron transfer process generates a sluggish kinetics ${ }^{3-5}$. In acid PEMWE, precious-metal oxides of $\mathrm{IrO}_{2}$ and $\mathrm{RuO}_{2}$ are currently regarded as the most active OER catalysts ${ }^{6}$. However, high costs and still poor intrinsic activities greatly limit their catalytic efficiencies. Therefore, developing efficient catalysts with less content of preciousmetal and higher intrinsic activity is quite appealing for acidic water oxidation.

Recently, the synthesis of complex oxides has been reported to be a promising approach for both reducing the precious-metal usage and promoting the intrinsic activity ${ }^{7-13}$. Various complex oxides with less precious-metal contents, including perovskite $\mathrm{e}^{7-10}$ and pyrochlore-type $\mathrm{e}^{11-13}$ compounds, were found to exhibit higher intrinsic OER activities relative to the simple binary oxides under acid conditions. For instance, the specific activity reached to about $2.8 \mathrm{~mA} \mathrm{~cm}^{-2}$ oxide at $1.55 \mathrm{~V}$ for perovskite oxide $\mathrm{Ba}_{2} \mathrm{~N}$ $\mathrm{dIrO}_{6}$, which is about 14 times larger than that of the commercial $\mathrm{IrO}_{2}\left(\sim 0.2 \mathrm{~mA} \mathrm{~cm}^{-2} \text { oxide }\right)^{8}$. A more efficient $\mathrm{IrO}_{x} / \mathrm{SrIrO}_{3}$ catalyst with a high specific current density of $10 \mathrm{~mA} \mathrm{~cm}^{-2}$ oxide at $1.50 \mathrm{~V}$ was revealed by strontium leaching from surface layers of $\mathrm{SrIrO}_{3}$ thin films during electrochemical testing 9 . Similar promotions were also observed in pyrochlore-type $\mathrm{Y}_{2} \mathrm{Ir}_{2} \mathrm{O}_{7}$ and $\mathrm{Y}_{2} \mathrm{Ru}_{2} \mathrm{O}_{7-\delta}$ catalysts ${ }^{12,13}$. Compared to iridium, ruthenium is much lower in price $^{4,6,13}$. Moreover, ruthenium oxide typically exhibits higher activity than iridium oxide ${ }^{4,6}$. Therefore, the ruthenium oxides with complex structures represent promising catalysts for acidic water oxidation.

In this work, we report a complex perovskite oxide $\mathrm{CaCu}_{3} \mathrm{Ru}_{4} \mathrm{O}_{12}$ as a highly efficient catalyst for OER in acid. Unexpectedly, this ruthenate catalyst presents an ultralow overpotential of $171 \mathrm{mV}$ at $10 \mathrm{~mA} \mathrm{~cm}^{-2}$ geo in $0.5 \mathrm{M} \mathrm{H}_{2} \mathrm{SO}_{4}$ solution, surpassing the most reported robust OER catalysts in acid up to date. Moreover, it achieves large mass activity of $1942 \mathrm{~A} \mathrm{~g}^{-1} \mathrm{Ru}$ and specific activity of $22.1 \mathrm{~mA} \mathrm{~cm}^{-2}$ oxide at $1.50 \mathrm{~V}$, which are 170 and 96 times higher than those of the commercial $\mathrm{RuO}_{2}$, respectively. The long-term durability tests also reveal that $\mathrm{CaCu}_{3} \mathrm{Ru}_{4} \mathrm{O}_{12}$ shows much better stability than $\mathrm{RuO}_{2}$. The excellent OER performance of this ruthenate oxide would make it a promising catalyst in commercial PEMWE.

\section{Results}

Synthesis and characterization. The ruthenate oxide $\mathrm{CaCu}_{3} \mathrm{Ru}_{4} \mathrm{O}_{12}$ belongs to the typical A-site ordered quadruple perovskite compound $\mathrm{AA}_{3}{ }_{3} \mathrm{~B}_{4} \mathrm{O}_{12}$, whose crystal structure can be considered as a $2 \times 2 \times 2$ superstructure of simple cubic perovskite $\mathrm{ABO}_{3}$. As shown in Fig. 1a, one $\mathrm{Ca}^{2+}$ and three $\mathrm{Cu}^{2+}$ ions occupy A-sites in order, while the $\mathrm{Ru}^{4+}$ ions form corner-share $\mathrm{RuO}_{6}$ octahedra at B-sites ${ }^{14,15}$. The polycrystalline powders of this compound were synthesized by a conventional solid-state reaction. Scanning electron microscopy (SEM) image displays that the particle sizes are submicron (Supplementary Fig. 1). Figure 1b shows the powder X-ray diffraction (XRD) of as-prepared sample, where all the diffraction lines are well indexed to the cubic (Im-3) phase without detectable amount of impurities. On the base of Rietveld refinements on diffraction data, the lattice parameter $a$ and $\mathrm{Ru}-\mathrm{O}$ bond length are determined to be 7.4206(3) and 1.9808 (7) $\AA$ (Supplementary Table 1), respectively, which well agrees with the reported values ${ }^{14}$. The good crystallinity and singlephase structure are further confirmed by high resolution transmission electron microscopy (HRTEM) image together with selected area electron diffraction (SAED) pattern (Fig. 1c). The observed lattice fringes with inter-plane spacing of $0.265 \mathrm{~nm}$ correspond to the $(02 \overline{2})$ or $(20 \overline{2})$ plane of cubic phase $\mathrm{CaCu}_{3} \mathrm{Ru}_{4} \mathrm{O}_{12}$. X-ray photoelectron spectra (XPS) measurements (Fig. 1d) reveal that $\mathrm{CaCu}_{3} \mathrm{Ru}_{4} \mathrm{O}_{12}$ exhibits two peaks at 464.2 and $486.3 \mathrm{eV}$, which are similar to those of $\mathrm{RuO}_{2}$ and assigned to $3 \mathrm{p}_{3 / 2}$ and $3 \mathrm{p}_{1 / 2}$ states of $\mathrm{Ru}^{4+}$ ions ${ }^{16}$, respectively. The energy dispersive X-ray spectrum (EDS, Supplementary Fig. 2) demonstrates that the molar ratio of $\mathrm{Ca} / \mathrm{Cu} / \mathrm{Ru}$ is $1: 2.98: 4.03$, which suggests a good stoichiometry of the as-synthesized sample.

OER performance. We evaluated the electrocatalytic OER activity of $\mathrm{CaCu}_{3} \mathrm{Ru}_{4} \mathrm{O}_{12}$ in $\mathrm{O}_{2}$-saturated $0.5 \mathrm{M} \mathrm{H}_{2} \mathrm{SO}_{4}$ solution using a standard three-electrode system. Figure $2 \mathrm{a}$ shows the polarization curve for $\mathrm{CaCu}_{3} \mathrm{Ru}_{4} \mathrm{O}_{12}$, along with the commercial $\mathrm{RuO}_{2}$ as a reference. For $\mathrm{RuO}_{2}$, a large overpotential $(\eta)$ of $316 \mathrm{mV}$ was required to achieve a current density of $10 \mathrm{~mA} \mathrm{~cm}^{-2}$ geo, which is in line with those previous reports (Supplementary Table 2). Intriguingly, for $\mathrm{CaCu}_{3} \mathrm{Ru}_{4} \mathrm{O}_{12}$, the current density is remarkably enhanced and the overpotential is much reduced to $171 \mathrm{mV}$. Moreover, by normalizing the current density to catalyst mass or $\mathrm{Ru}$ metal mass, a significant increase in the mass activity is observed (Supplementary Fig. 3). For example, the mass activity of $\mathrm{CaCu}_{3} \mathrm{Ru}_{4} \mathrm{O}_{12}$ achieves $1942 \mathrm{~A} \mathrm{~g}^{-1}{ }_{\mathrm{Ru}}$ at $1.50 \mathrm{~V}$, which is 170 times higher than that of $\mathrm{RuO}_{2}\left(11.4 \mathrm{Ag}^{-1} \mathrm{Ru}\right)$. As shown by Tafel plots in Fig. $2 b$, this enhanced performance is further verified to be intrinsic by the specific activity, which is obtained from normalizing the mass activity with Brunauer-Emmett-Teller (BET) surface area (Supplementary Fig. 4). Notably, the specific current density of $\mathrm{CaCu}_{3} \mathrm{Ru}_{4} \mathrm{O}_{12}$ at $1.50 \mathrm{~V}$ reaches up to the value of $22.1 \mathrm{~mA} \mathrm{~cm}^{-2}$ oxide, which is 96 times larger than that of $\mathrm{RuO}_{2}$ $\left(0.23 \mathrm{~mA} \mathrm{~cm}^{-2}\right.$ oxide). The similar feature is also found in the specific activities normalized by the electrochemically active surface areas (ECSA), which are derived from the electrochemical double-layer capacitance measurements (Supplementary Fig. 5, 6). Meanwhile, the Tafel plots illustrate that $\mathrm{CaCu}_{3} \mathrm{Ru}_{4} \mathrm{O}_{12}$ presents a smaller Tafel slope of $40 \mathrm{mV} \mathrm{dec}-1$ than $\mathrm{RuO}_{2}$ of $67 \mathrm{mV} \mathrm{dec}^{-1}$, suggesting its significantly accelerated OER kinetic. The faster OER kinetic rate is further reflected by the electrochemical impedance spectroscopy (EIS) measurements, where a remarkable decrease of charge transfer resistance (Rct) is revealed for the ruthenate catalyst (Supplementary Fig. 7).

Our electrochemical tests clearly demonstrate that $\mathrm{CaCu}_{3} \mathrm{Ru}_{4} \mathrm{O}_{12}$ exhibits a superior activity for acidic water oxidation. To the best of our knowledge, this complex oxide has the lowest overpotential at $10 \mathrm{~mA} \mathrm{~cm}^{-2}$ geo among the excellent OER catalysts in acid electrolytes as reported up to date (Fig. 2c and Supplementary Table 3). Furthermore, its intrinsic activity also outperforms all of them. Particularly, the specific current density of the ruthenate at $1.50 \mathrm{~V}$ is even about two-fold higher than that of the recently reported best oxide catalyst $\mathrm{IrO}_{x} / \mathrm{SrIrO}_{3}$ (Supplementary Table 3).

To access the electrochemical stability of $\mathrm{CaCu}_{3} \mathrm{Ru}_{4} \mathrm{O}_{12}$, we performed a long-term chronopotentiometry at a constant current density of $10 \mathrm{~mA} \mathrm{~cm}^{-2}$, together with $\mathrm{RuO}_{2}$ for comparison. As shown in Fig. 2d, the commercial $\mathrm{RuO}_{2}$ nearly loses all its activity after $1 \mathrm{~h}$. In constrast, the overpotential for $\mathrm{CaCu}_{3} \mathrm{Ru}_{4} \mathrm{O}_{12}$ just slightly increases from 171 to $192 \mathrm{mV}$ after a $24 \mathrm{~h}$ continuous operation. The high stability of this complex oxide is also supported by the XRD, XPS, and HRTEM measurements after the OER test. No visible changes in the positions of XRD diffraction lines and XPS core level peaks (Supplementary Fig. 8) are found on the materials before and after the OER testing, while there is a marked decrease in the intensities due to the less catalyst mass used in the measurements 


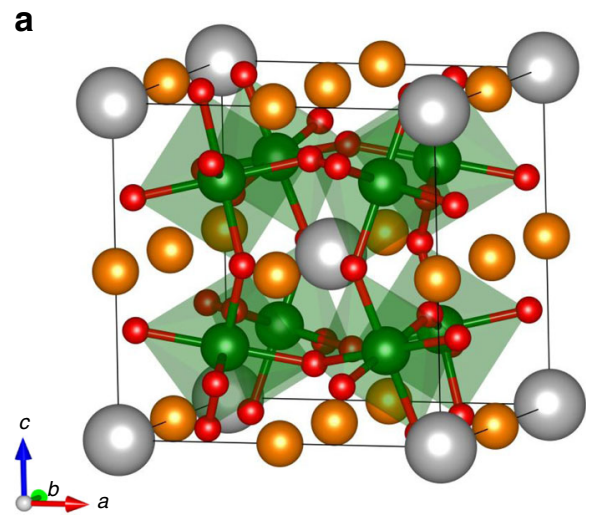

b


Fig. 1 Structural characterization of $\mathrm{CaCu}_{3} \mathrm{Ru}_{4} \mathrm{O}_{12}$. a Crystal structure of $\mathrm{CaCu}_{3} \mathrm{Ru}_{4} \mathrm{O}_{12}$. Color code: $\mathrm{Ca}$ (gray), $\mathrm{Cu}$ (bronze), $\mathrm{Ru}$ (green), and O (red). b XRD pattern for $\mathrm{CaCu}_{3} \mathrm{Ru}_{4} \mathrm{O}_{12}$ together with the Rietveld refined results. c HRTEM image and SAED pattern (inset) for $\mathrm{CaCu}_{3} \mathrm{Ru}_{4} \mathrm{O}_{12}$. The scale bar is $2 \mathrm{~nm}$. $\mathbf{d} \mathrm{Ru}$ 3p XPS spectra

after the OER testing. HRTEM image (Supplementary Fig. 9) further shows that the lattice fringes for the $\mathrm{CaCu}_{3} \mathrm{Ru}_{4} \mathrm{O}_{12}$ particle after the durability test still extend all the way to the surface, which suggests that the surface structure of $\mathrm{CaCu}_{3} \mathrm{Ru}_{4} \mathrm{O}_{12}$ is maintained during OER. In addition, inductively coupled plasma atomic emission spectroscopy (ICP-AES) measurements (Supplementary Table 4) reveal that less than $6.7 \% \mathrm{Ca}, 2.9 \% \mathrm{Cu}$, and $2.7 \% \mathrm{Ru}$ ions are found to be dissolved in the electrolyte, indicating just a slight cation leaching during the OER operation. This is also confirmed by TEM-EDS spectrum (Supplementary Fig. 10), which shows a small change of $\mathrm{Ca} / \mathrm{Cu} / \mathrm{Ru}$ ratio for ruthenate catalyst after the acidic OER testing. These results suggest that this ruthenate oxygen-evolving catalyst shows good chemical stability in acid, which will be beneficial for the commercial applications.

\section{Discussion}

To understand the enhanced OER activity in the complex oxide $\mathrm{CaCu}_{3} \mathrm{Ru}_{4} \mathrm{O}_{12}$, density functional theory (DFT) calculations were carried out. Figures $3 a, b$ show the computed density of states (DOS) for $\mathrm{RuO}_{2}$ and $\mathrm{CaCu}_{3} \mathrm{Ru}_{4} \mathrm{O}_{12}$, respectively. The large DOS from $\mathrm{Ru} 4 \mathrm{~d}$ and $\mathrm{O} 2 \mathrm{p}$ bands cross the Fermi level for both the oxides, which indicates that they present an intrinsically metallic behavior. However, compared to $\mathrm{RuO}_{2}, \mathrm{CaCu}_{3} \mathrm{Ru}_{4} \mathrm{O}_{12}$ exhibits a downshift in the projected DOS for both Ru $4 \mathrm{~d}$ band and $\mathrm{O} 2 \mathrm{p}$ band relative to the Fermi level. For $\mathrm{RuO}_{2}$, the calculated $\mathrm{Ru} 4 \mathrm{~d}$ band and $\mathrm{O} 2 \mathrm{p}$ band centers are 0.72 and $0.16 \mathrm{eV}$, while the values are reduced to -1.37 and $-3.42 \mathrm{eV}$ for $\mathrm{CaCu}_{3} \mathrm{Ru}_{4} \mathrm{O}_{12}$, respectively. To confirm these electronic features, we further conducted the electrical transport measurements. Figure $3 \mathrm{c}$ plots the temperature-dependent resistivity for $\mathrm{RuO}_{2}$ and
$\mathrm{CaCu}_{3} \mathrm{Ru}_{4} \mathrm{O}_{12}$. Upon cooling, their electrical resistivities show a monotonous decrease. This temperature dependence reveals an intrinsic metallic state for both the oxides, agreeing well with the DFT calculations. The metallic conductivity could ensure fast charge transfer between catalyst-electrolyte and catalyst-support electrode interfaces, which is beneficial for the OER process ${ }^{17}$. Moreover, the resistivity of $\mathrm{CaCu}_{3} \mathrm{Ru}_{4} \mathrm{O}_{12}$ is apparently higher than that of $\mathrm{RuO}_{2}$ within the measured temperature range. For example, $\mathrm{CaCu}_{3} \mathrm{Ru}_{4} \mathrm{O}_{12}$ exhibits a more than threefold increase in the resistivity $(1.5 \mathrm{~m} \Omega \mathrm{cm})$ at room temperature compared to $\mathrm{RuO}_{2}(0.43 \mathrm{~m} \Omega \mathrm{cm})$. The larger resistivity is supposed to be associated with the $\mathrm{Ru} 4 \mathrm{~d}$ and $\mathrm{O} 2 \mathrm{p}$ band centers far away from the Fermi level owing to their downshifts to low energies.

During the OER process, the conventional adsorbate mechanism demonstrates that the electrochemical activity of catalysts is determined by the binding strengths of adsorbed intermediates such as $\mathrm{HO}^{*}, \mathrm{O}^{*}$, and $\mathrm{HOO}^{*}$ to active sites ${ }^{18-22}$. For transition metal oxide OER catalysts, the d-band center of active metal sites is closely related to the binding strength between metal sites and adsorbed oxygen species ${ }^{22-24}$. Usually, a lower d-band center generates a weaker metal-oxygen binding 22-24. In our case, the refined $\mathrm{Ru}-\mathrm{O}$ bond length of $\mathrm{CaCu}_{3} \mathrm{Ru}_{4} \mathrm{O}_{12}$ is $1.9808(7) \AA$, which is longer than the average $\mathrm{Ru}-\mathrm{O}$ bond length of $\mathrm{RuO}_{2}(\sim 1.97 \AA)^{25,26}$. This implies that $\mathrm{CaCu}_{3} \mathrm{Ru}_{4} \mathrm{O}_{12}$ has a weaker $\mathrm{Ru}-\mathrm{O}$ bonding strength compared to $\mathrm{RuO}_{2}$, well associated with that the former has a lower $\mathrm{Ru} 4 \mathrm{~d}-$ band center. To further assess the strength of $\mathrm{Ru}-\mathrm{O}$ bonds in our catalysts, we performed the O K-edge X-ray absorption spectroscopy (XAS). O $1 \mathrm{~s}$ spectra in K-edge XAS reflect the transition from $\mathrm{O} 1 \mathrm{~s}$ core level to unoccupied $\mathrm{O} 2 \mathrm{p}$ states hybridized with metal ions ${ }^{27,28}$. A higher absorption intensity of $\mathrm{O} 1 \mathrm{~s}$ spectra suggests a stronger hybridization between oxygen and metal ions. 

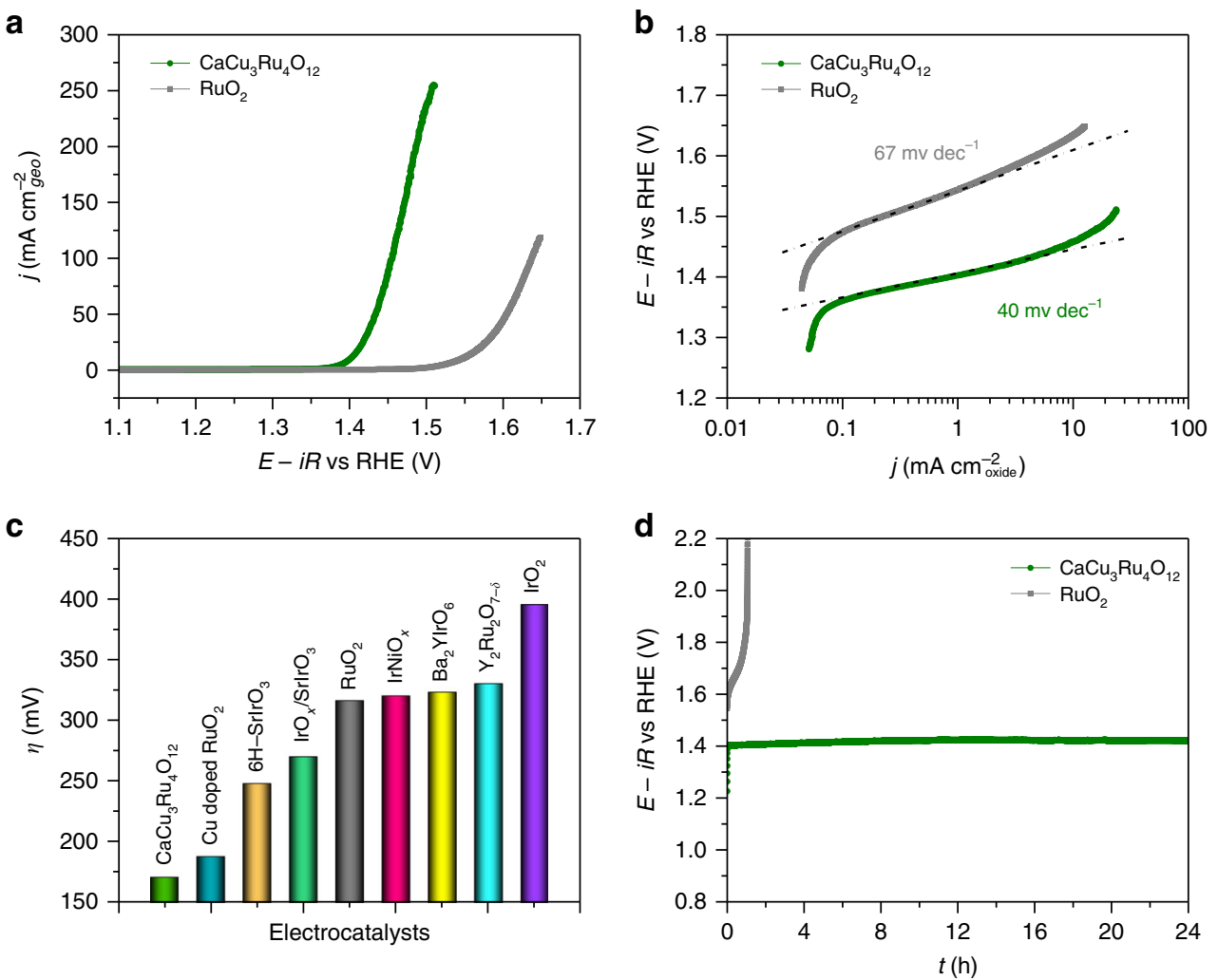

Fig. 2 Electrochemical OER performance. a Polarization curves of $\mathrm{CaCu}_{3} \mathrm{Ru}_{4} \mathrm{O}_{12}$ and the commercial $\mathrm{RuO}_{2}$ measured in $\mathrm{O}_{2}$-saturated $0.5 \mathrm{M} \mathrm{H} \mathrm{H}_{2} \mathrm{SO}_{4}$ solution. b Tafel plots of specific OER activity. c Comparison of the overpotentials at $10 \mathrm{~mA} \mathrm{~cm}^{-2}$ geo for $\mathrm{CaCu}_{3} \mathrm{Ru}_{4} \mathrm{O}_{12}$ and recent reported OER catalysts in acid media. d Chronopotentiometric measurements of $\mathrm{CaCu}_{3} \mathrm{Ru}_{4} \mathrm{O}_{12}$ and the commercial $\mathrm{RuO}_{2}$ at $10 \mathrm{~mA} \mathrm{~cm}^{-2}$ geo

a
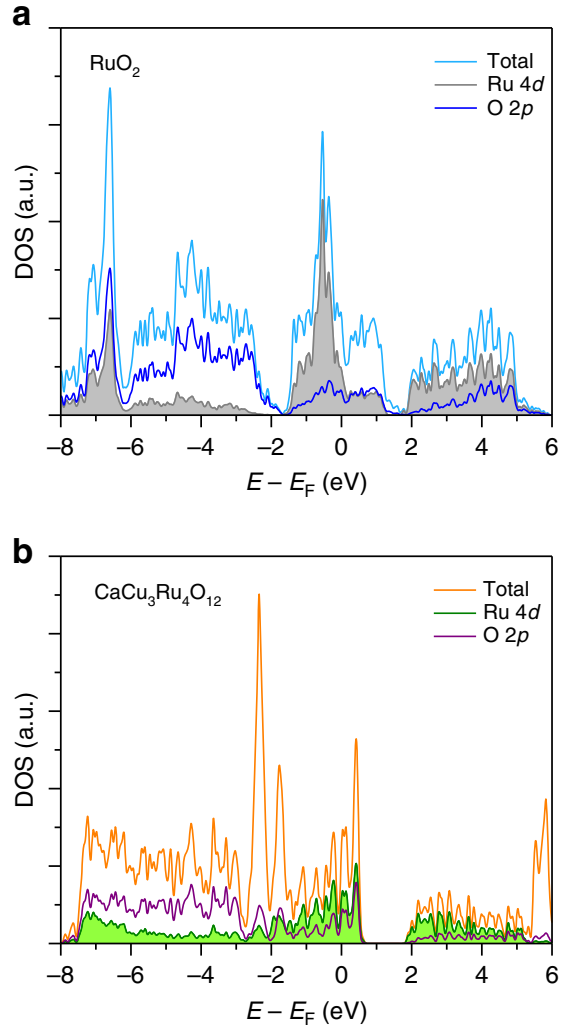

C

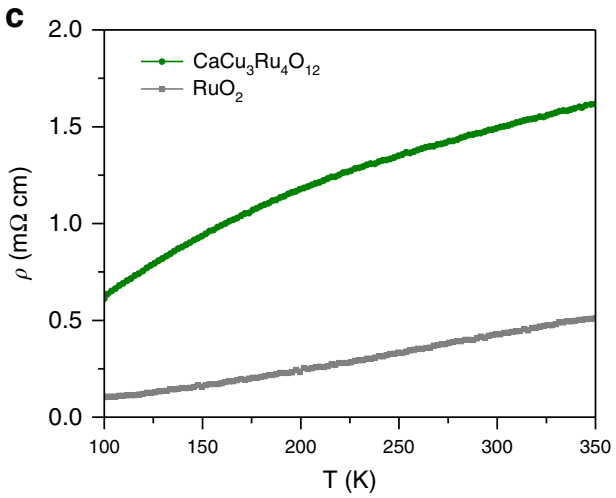

d

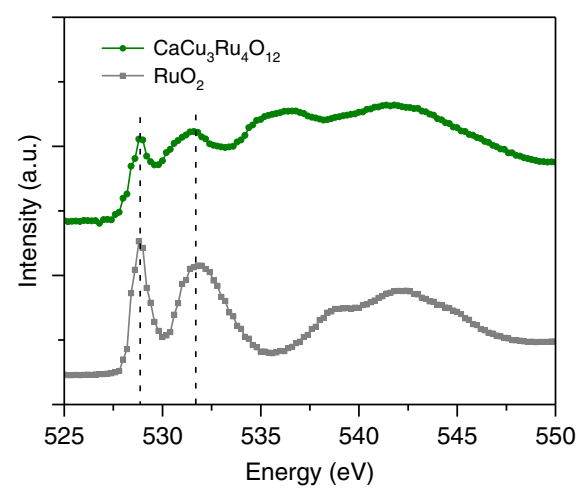

Fig. 3 Electronic structure studies. $\mathbf{a}$, b Computed density of states (DOS) of $\mathbf{a} \mathrm{RuO}_{2}$ and $\mathbf{b} \mathrm{CaCu}_{3} \mathrm{Ru}_{4} \mathrm{O}_{12}$. $\mathbf{c}$ Temperature dependence of resistivity. $\mathbf{d} \mathrm{O}$ K-edge XAS 
As shown in Fig. 3d, two pre-edge peaks are clearly observed at 528.8 and $531.7 \mathrm{eV}$ for our catalysts, which are assigned to the unoccupied orbitals of $\mathrm{O} 2 \mathrm{p}$ hybridized with $\mathrm{Ru} 4 \mathrm{~d} \mathrm{t}_{2 \mathrm{~g}}$ and $\mathrm{e}_{\mathrm{g}}$ orbitals $^{29,30}$, respectively. The intensities of pre-edge peaks normalized by the adsorption background at the energy ranges both below the absorption edge and at $\sim 550 \mathrm{eV}^{27,28,31}$ are used to estimate the hybridization of $\mathrm{O} 2 \mathrm{p}$ with $\mathrm{Ru} 4 \mathrm{~d}$ orbitals. Obviously, the normalized intensities for $\mathrm{CaCu}_{3} \mathrm{Ru}_{4} \mathrm{O}_{12}$ are much smaller than those for $\mathrm{RuO}_{2}$, which implies that the $\mathrm{Ru}-\mathrm{O}$ bonds in the complex oxide have a less hybridization. This feature further supports that a weaker $\mathrm{Ru}-\mathrm{O}$ binding strength occurs in $\mathrm{CaCu}_{3} \mathrm{Ru}_{4} \mathrm{O}_{12}$ owing to its lower $\mathrm{Ru} 4 \mathrm{~d}$ band center.

To elucidate the role of the electronic structures on OER energetics for our Ru-based oxides, theoretical OER overpotentials were further evaluated from DFT calculations. According to the previous studies ${ }^{18-22}$, we assumed a four-step OER mechanism, which proceeds through four consecutive proton and electron transfer steps with $\mathrm{HO}^{*}, \mathrm{O}^{*}$, and $\mathrm{HOO}^{*}$ intermediates. The Gibbs free energies of different intermediates adsorbed by surface $\mathrm{Ru}$ atoms for both catalysts were calculated with the standard hydrogen electrode (SHE) method ${ }^{32,33}$. Firstly, we focused on $\mathrm{RuO}_{2}$ (110) and $\mathrm{CaCu}_{3} \mathrm{Ru}_{4} \mathrm{O}_{12}$ (001) surfaces (Supplementary Fig. 11, 12), since they are considered as the relatively more stable facets for rutile and pervoskite oxides $^{16,19,20}$, respectively. Figure $4 \mathrm{a}$, b illustrates the free energy diagrams calculated on both the surfaces. For $\mathrm{RuO}_{2}$, all reaction steps move uphill in free energy at zero potential. Moreover, the free energy difference between $\Delta G_{\mathrm{HOO}^{*}}$ and $\Delta G_{\mathrm{O}^{*}}$ is found to be maximum, i.e., $\Delta G_{\mathrm{HOO}^{*}}-\Delta G_{\mathrm{O}^{*}}=2.08 \mathrm{eV}$, indicating that a minimum potential of $U=2.08 \mathrm{~V}$ has to be applied to make every step downhill in free energy. This means that the formation of $\mathrm{HOO}^{*}$ from $\mathrm{O}^{*}$ intermediates is the rate-determining step (RDS), which results in a high OER overpotential of $0.85 \mathrm{~V}$. Our calculations on $\mathrm{RuO}_{2}$ are in accord with previous reports ${ }^{16,34,35}$. For $\mathrm{CaCu}_{3} \mathrm{Ru}_{4} \mathrm{O}_{12}$, the formation of $\mathrm{HOO}^{*}$ intermediates is still the
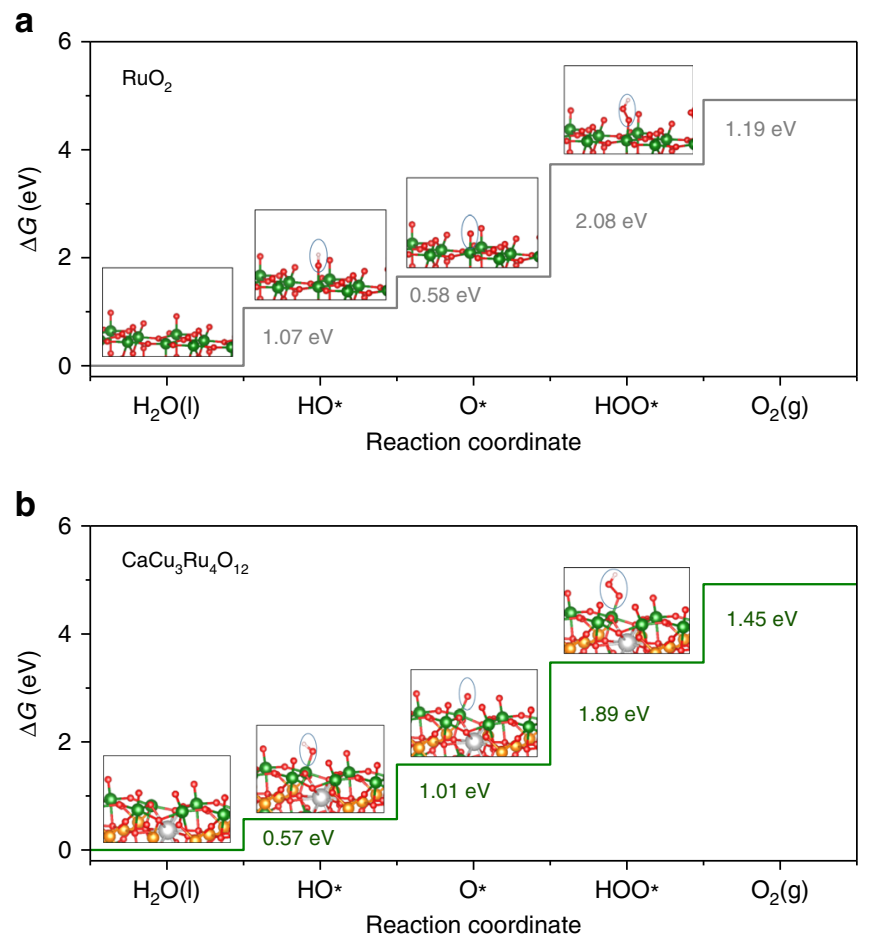

Fig. 4 Calculated free energy diagrams. a $\mathrm{RuO}_{2}$. b $\mathrm{CaCu}_{3} \mathrm{Ru}_{4} \mathrm{O}_{12}$. The optimized structures of $\mathrm{HO}^{*}, \mathrm{O}^{*}$, and $\mathrm{HOO}^{*}$ adsorptions on the surfaces are shown in the insets
RDS. However, $\Delta G_{\mathrm{HOO}^{*}}-\Delta G_{\mathrm{O}^{*}}$ is significantly reduced to $1.89 \mathrm{eV}$, corresponding to a theoretical overpotential of $0.66 \mathrm{~V}$. These calculated results imply that compared to $\mathrm{RuO}_{2}$ the quadruple perovskite ruthenate exhibits a much reduction in the OER overpotential by $0.19 \mathrm{~V}$. Notably, our calculated OER overpotentials are different from the experimental values possibly because the formers are just obtained from the thermodynamic analyses ${ }^{10}$. However, the magnitude of reduction in the overpotentials is comparable between them $(0.19 \mathrm{~V}$ vs $0.145 \mathrm{~V})$, which supports that the unique electronic structure associated with the quadruple perovskite crystal structure for $\mathrm{CaCu}_{3} \mathrm{Ru}_{4} \mathrm{O}_{12}$ would be responsible for the observed superior OER activity.

Additionally, we also carried out the DFT calculations on other facets for both the catalysts. For $\mathrm{RuO}_{2}$, as shown in Supplementary Fig. 13, 14, the free energy diagrams for less stable (001) and (100) surfaces illustrate that the theoretical overpotentials are 1.00 and $0.74 \mathrm{~V}$, respectively, which are still larger than that of $\mathrm{CaCu}_{3} \mathrm{Ru}_{4} \mathrm{O}_{12}$ (001) surface. For $\mathrm{CaCu}_{3} \mathrm{Ru}_{4} \mathrm{O}_{12}$, the calculations on (110) surface (Supplementary Fig. 15) reveal that this highindex facet exhibits an inferior OER activity with a theoretical overpotential of $0.85 \mathrm{~V}$. Furthermore, in order to evaluate the role of $\mathrm{Ca}$ and $\mathrm{Cu}$ cations on the OER activity, we calculated the free energy diagrams on $\mathrm{Ca}$ and $\mathrm{Cu}$ sites for $\mathrm{CaCu}_{3} \mathrm{Ru}_{4} \mathrm{O}_{12}(001)$ surface, as shown in Supplementary Fig. 16, 17. The theoretical overpotentials are estimated to be 0.99 and $0.92 \mathrm{~V}$, respectively, which both are much larger than that on $\mathrm{Ru}$ sites $(0.66 \mathrm{~V})$. This result strongly supports that $\mathrm{Ru}$ cations are the OER active sites for $\mathrm{CaCu}_{3} \mathrm{Ru}_{4} \mathrm{O}_{12}$.

Recent theoretical studies on the OER mechanism for transition metal oxides have demonstrated that the $\Delta G_{\mathrm{O}^{*}}-\Delta G_{\mathrm{HO}^{*}}$ difference can effectively describe their OER activities since there is a strong relations between $\Delta G_{\mathrm{HO}^{*}}$ and $\Delta G_{\mathrm{HOO}^{*}}{ }^{19-22}$. Actually, this difference reflects the metal-oxygen binding strength ${ }^{22}$. The optimal catalysts are required to have neither too strong nor too weak binding strengths. Too strong metal-oxygen bond strength would result in a small $\Delta G_{\mathrm{O}^{*}}-\Delta G_{\mathrm{HO}^{*}}$ difference and then a large $\Delta G_{\mathrm{HOO}^{*}}-\Delta G_{\mathrm{O}^{*}}$ difference. Our DFT calculations reveal $\mathrm{CaCu}_{3} \mathrm{Ru}_{4} \mathrm{O}_{12}$ exhibits a much reduction in $\Delta G_{\mathrm{HOO}^{*}}-\Delta G_{\mathrm{O}^{*}}$ difference with comparison to $\mathrm{RuO}_{2}$. Moreover, this reduction is accompanied by a large increase in $\Delta G_{\mathrm{O}^{*}}-\Delta G_{\mathrm{HO}^{*}}$ from 0.58 to $1.01 \mathrm{eV}$. In other words, the weaker $\mathrm{Ru}-\mathrm{O}$ coupling in $\mathrm{CaCu}_{3} \mathrm{Ru}_{4} \mathrm{O}_{12}$ leads to a larger $\Delta G_{\mathrm{O}^{*}}-\Delta G_{\mathrm{HO}^{*}}$ and then a smaller $\Delta G_{\mathrm{HOO}^{*}}-\Delta G_{\mathrm{O}^{*}}$, i.e., a smaller overpotential. Therefore, we conclude that the weaker binding strength between oxygen species and $\mathrm{Ru}$ sites due to the lower $\mathrm{Ru} 4 \mathrm{~d}$ band center gives rise to the higher intrinsic activity of quadruple perovskite $\mathrm{CaCu}_{3} \mathrm{Ru}_{4} \mathrm{O}_{12}$. In addition, previous studies revealed that the instability for $\mathrm{RuO}_{2}$ may be attributed to the high $\mathrm{Ru}$ dissolution rate due to oxygen vacancies arising from the participation of activated lattice oxygen in OER process ${ }^{36}$. For transition metal oxides, the strong metal-oxygen couplings were reported to easily trigger the lattice oxygen redox during $\mathrm{OER}^{37}$. We thus suppose that the weaker $\mathrm{Ru}-\mathrm{O}$ binding strength in $\mathrm{CaCu}_{3} \mathrm{Ru}_{4} \mathrm{O}_{12}$ may also lower the $\mathrm{Ru}$ dissolution rate owing to the less participation of lattice oxygen redox in the OER process, which will improve its stability in acid.

In summary, we develop a complex ruthenate $\mathrm{CaCu}_{3} \mathrm{Ru}_{4} \mathrm{O}_{12}$ as an efficient OER catalyst with excellent activity and good durability in acidic media. It only requires an ultralow overpotential of $171 \mathrm{mV}$ to yield a current density of $10 \mathrm{~mA} \mathrm{~cm}^{-2}$ geo under $\mathrm{pH}=0$. The mass activity reaches up to $1942 \mathrm{~A} \mathrm{~g}^{-1} \mathrm{Ru}$ at $1.50 \mathrm{~V}$, which is 170 times higher than that of the state-of-the-art $\mathrm{RuO}_{2}$. Moreover, this complex oxide exhibits much better stability than $\mathrm{RuO}_{2}$. Electronic structure studies and DFT calculations reveal that compared to that of $\mathrm{RuO}_{2}$, the adsorption of oxygen intermediates for $\mathrm{CaCu}_{3} \mathrm{Ru}_{4} \mathrm{O}_{12}$ is significantly weakened due to its 
lower $\mathrm{Ru} 4 \mathrm{~d}$-band center, which facilitates the sluggish kinetics of oxygen-evolving process and enhances the intrinsic activity. This work not only demonstrates that the quadruple perovskite ruthenate holds great potential in the commercial application of PEMWE, but also provides a guidance for exploiting superior oxygen-evolving catalysts from the materials with complex structures.

\section{Methods}

Synthesis and characterizations. The polycrystalline powders of quadruple perovskite oxide $\mathrm{CaCu}_{3} \mathrm{Ru}_{4} \mathrm{O}_{12}$ were prepared by a conventional solid-state reaction. Stoichiometric mixtures of $0.2002 \mathrm{~g} \mathrm{CaCO}_{3}, 0.4773 \mathrm{~g} \mathrm{CuO}$, and $1.0645 \mathrm{~g} \mathrm{RuO}_{2}$ were thoroughly ground and sintered in static and ambient air at $1000^{\circ} \mathrm{C}$ for $24 \mathrm{~h}$. Then, the obtained powders were reground and calcined in static and ambient air at $1000^{\circ} \mathrm{C}$ for $24 \mathrm{~h}$ to produce the sample. All the products were furnace-cooled to room temperature and ground by hand. The powder XRD patterns were collected on a Rigaku TTR-III diffractometer equipped with a $\mathrm{Cu} \mathrm{Ka}$ radiation source $(\lambda=$ $1.5418 \AA$ A). The SEM images were obtained on the field emission scanning electron microscope (JEOL-2010 SEM) operated at $5 \mathrm{kV}$. The SEM specimens were prepared by depositing the catalyst powders on conductive carbon adhesive tape. HRTEM images and SAED patterns were acquired using a transmission electron microscope (JEOL, JEM-ARM200F) with a spherical aberration corrector at an acceleration voltage of $200 \mathrm{kV}$. For TEM specimen preparation, the catalyst powders were firstly dispersed in ethanol by sonication and then dropped onto a carbon-coated molybdenum grid with micropipettes, followed by drying under ambient conditions. XPS were carried out on an ESCALAB $250 \mathrm{X}$-ray photoelectron spectrometer using an $\mathrm{Al} \mathrm{Ka}$ X-ray source. For XPS analysis, the binding energies were calibrated by referencing the C $1 \mathrm{~s}$ peak to $284.8 \mathrm{eV}$ and no background subtraction was performed. The nitrogen adsorption-desorption isotherms were recorded at $77 \mathrm{~K}$ according to the preset pressure procedure using a Micromeritics ASAP 2000 system. Prior to the measurements, the samples were outgassed at $300{ }^{\circ} \mathrm{C}$ under vacuum for $10 \mathrm{~h}$. The total surface areas were deduced from the isotherm analysis over the range of the relative pressure from 0.05 to 0.20 . ICPAES was performed on a Perkin-Elmer Optima 3300DV ICP spectrometer. The temperature-dependent resistivities of pelleted samples were measured on a Quantum Design Physical Property Measurement System by using the four-probe method. O K-edge XAS were measured at the beamline BL12B of National Synchrotron Radiation Laboratory (NSRL, Hefei) in the total electron yield mode by collecting the sample drain current under a vacuum better than $10^{-7} \mathrm{~Pa}$. The beam from the bending magnet was monochromatized by utilizing a varied line-spacing plane grating and refocused by a toroidal mirror. The spectra from 525 to $550 \mathrm{eV}$ were scanned with an energy resolution of $0.2 \mathrm{eV}$. To eliminate the effect of different sample concentration and measurement conditions on the intensity of XAS peaks, all the spectra were normalized to the adsorption background at the energy ranges both below the absorption edge and at $\sim 550 \mathrm{eV}$ as described in the literatures $27,28,31$. The XAS specimens were prepared by placing a small amount of catalyst powders on a conductive carbon tape, which was mounted on an aluminum holder attached to the main chamber manipulator.

Electrochemical measurements. The electrochemical tests were performed with a three-electrode on the CHI660E electrochemical station. Saturated $\mathrm{Hg} / \mathrm{Hg}_{2} \mathrm{SO}_{4}$ and platinum wires were used as the reference and the counter electrodes, respectively. The $\mathrm{Hg} / \mathrm{Hg}_{2} \mathrm{SO}_{4}$ reference electrode was calibrated in $\mathrm{H}_{2}$-saturated $0.5 \mathrm{M} \mathrm{H}_{2} \mathrm{SO}_{4}$ solution with a $\mathrm{Pt}$ wire as working electrode. The measured potentials vs $\mathrm{Hg} /$ $\mathrm{Hg}_{2} \mathrm{SO}_{4}$ were converted to the values with reference to a reversible hydrogen electrode (RHE). In $0.5 \mathrm{M} \mathrm{H}_{2} \mathrm{SO}_{4}, E_{\mathrm{RHE}}=E_{\mathrm{Hg} / \mathrm{Hg} 2 \mathrm{SO} 4}+0.652 \mathrm{~V}$. To prepare the working electrode, the catalysts $(18.5 \mathrm{mg})$, activated carbon $(3.7 \mathrm{mg})$, and Nafion $(5 \mathrm{wt} \%, 100 \mu \mathrm{L})$ were dispersed in $5 \mathrm{~mL}$ tetrahydrofuran (THF) with sonication for $30 \mathrm{~min}$ to generate a homogenous ink. Then $5 \mu \mathrm{L}$ ink was drop-casted onto a glassy carbon electrode of $3 \mathrm{~mm}$ in diameter and dried naturally, yielding a catalyst loading of $0.25 \mathrm{mg} \mathrm{cm}^{-2}$. Linear sweeping voltammograms were obtained at a scan rate of $5 \mathrm{mV} \mathrm{s}^{-1}$. The potentials are $i R$-corrected to compensate for the effect of solution resistance, which were calculated by the following equation:

$$
E_{i R-\text { corrected }}=E-i R,
$$

where $i$ is the current, and $R$ is the uncompensated ohmic electrolyte resistance $(\sim 8 \Omega)$ measured via high frequency ac impedance in $\mathrm{O}_{2}$-saturated $0.5 \mathrm{M} \mathrm{H}_{2} \mathrm{SO}_{4}$ solution. EIS measurements were carried out at different potential values with the frequency ranging from $100 \mathrm{kHz}$ to $100 \mathrm{mHz}$ under an $\mathrm{AC}$ voltage of $5 \mathrm{mV}$. The impedance spectra were presented in the form of Nyquist plot and fitted using ZView software with a representative equivalent electrical circuit. ECSA was determined by measuring the capacitive current associated with double-layer charging from the scan-rate dependence of cyclic voltammetry $(\mathrm{CV})^{10,17}$. The potential window of CV was set to be $1.21-1.31 \mathrm{~V}$ vs RHE and the scan rates were $10,20,40,60,80$, and $100 \mathrm{mV} \mathrm{s}^{-1}$. The double-layer capacitance $\left(\mathrm{C}_{\mathrm{dl}}\right)$ was estimated by plotting the $\Delta j=\left(j_{+}-j_{-}\right) / 2$ at $1.26 \mathrm{~V}$ vs RHE against the scan rate. The
ECSA was calculated by the following equation:

$$
\text { ECSA }=\left(\mathrm{C}_{\mathrm{dl}} / \mathrm{C}_{\mathrm{s}}\right) / \mathrm{M},
$$

where $\mathrm{C}_{\mathrm{s}}$ and $\mathrm{M}$ represented the specific capacitance and the loading mass for the catalyst, respectively. A C $\mathrm{C}_{\mathrm{s}}$ value of $60 \mu \mathrm{F} \mathrm{cm}^{-2}$ was used as the common estimate for oxide surfaces ${ }^{38,39}$. To conduct the long-term chronopotentiometric measurements the catalysts were deposited on carbon paper with a mass loading of $0.25 \mathrm{mg} \mathrm{cm}^{-2}$ and followed by a heat-treating in ambient air at $300^{\circ} \mathrm{C}$. To carry out XRD and XPS measurements after the durability test for the catalysts, we followed the approaches frequently reported in recent literatures $7,12,13$, where the catalysts were loaded onto carbon paper with a high loading of $1 \mathrm{mg} \mathrm{cm}^{-2}$ for the durability test. After washing with ethanol and sonication, the specimens of $\sim 2 \mathrm{mg}$ were collected to use.

Computational methods. All the density functional theory (DFT) calculations were performed with the Vienna Ab-initio Simulation Package (VASP). The projector augmented wave (PAW) potentials and Perdew-Burke-Ernzerhof (PBE) exchange-correlation functional were adopted. All calculations were conducted using a plane-wave kinetic energy cutoff of $520 \mathrm{eV}$. The energy convergence criterion was set to be $10^{-5} \mathrm{eV}$, and the force on each ion was converged to less than $0.05 \mathrm{eV} / \mathrm{A}$. The relevant details, models, and references are given in the Supplementary Methods section.

\section{Data availability}

The data that support the findings of this study are available from the corresponding author on request.

Received: 7 January 2019 Accepted: 30 July 2019

Published online: 23 August 2019

\section{References}

1. Carmo, M., Fritz, D. L., Mergel, J. \& Stolten, D. A comprehensive review on PEM water electrolysis. Int. J. Hydrog. Energy 38, 4901-4934 (2013).

2. Montoya, J. H. et al. Materials for solar fuels and chemicals. Nat. Mater. 16, 70-81 (2017).

3. Park, S., Shao, Y., Liu, J. \& Wang, Y. Oxygen electrocatalysts for water electrolyzers and reversible fuel cells: status and perspective. Energy Environ. Sci. 5, 9331-9344 (2012).

4. McCrory, C. C. L. et al. Benchmarking hydrogen evolving reaction and oxygen evolving reaction electrocatalysts for solar water splitting devices. J. Am. Chem. Soc. 137, 4347-4357 (2015).

5. Seh, Z. W. et al. Combining theory and experiment in electrocatalysis: insights into materials design. Science 355, eaad4998 (2017).

6. Lee, Y., Suntivich, J., May, K. J., Perry, E. E. \& Shao-Horn, Y. Synthesis and activities of rutile $\mathrm{IrO} 2$ and $\mathrm{RuO} 2$ nanoparticles for oxygen evolution in acid and alkaline solutions. J. Phys. Chem. Lett. 3, 399-404 (2012).

7. Grimaud, A. et al. Activation of surface oxygen sites on an iridium-based model catalyst for the oxygen evolution reaction. Nat. Energy 2, 16189 (2017).

8. Diaz-Morales, O. et al. Iridium-based double perovskites for efficient water oxidation in acid media. Nat. Commun. 7, 12363 (2016).

9. Seitz, L. C. et al. A highly active and stable $\mathrm{IrOx} / \mathrm{SrIrO} 3$ catalyst for the oxygen evolution reaction. Science 353, 1011-1014 (2016).

10. Yang, L. et al. Efficient oxygen evolution electrocatalysis in acid by a perovskite with face-sharing IrO6 octahedral dimers. Nat. Commun. 9, 5236 (2018).

11. Lebedev, D. et al. Highly active and stable iridium pyrochlores for oxygen evolution reaction. Chem. Mater. 29, 5182-5191 (2017).

12. Shih, P.-C., Kim, J., Sun, C.-J. \& Yang, H. Single-phase pyrochlore Y2Ir2O7 electrocatalyst on the activity of oxygen evolution reaction. ACS Appl. Energy Mater. 1, 3992-3998 (2018).

13. Kim, J. et al. High-performance pyrochlore-type yttrium ruthenate electrocatalysts for oxygen evolution reaction in acidic media. J. Am. Chem. Soc. 139, 12076-12083 (2017)

14. Ebbinghaus, S. G., Weidenkaff, A. \& Cava, R. J. Structural investigations of ACu3Ru4O12 ( $\mathrm{A}=\mathrm{Na}, \mathrm{Ca}, \mathrm{Sr}, \mathrm{La}, \mathrm{Nd})$ - A comparison between XRD-Rietveld and EXAFS results. J. Solid State Chem. 167, 126-136 (2002).

15. Subramanian, M. A. \& Sleight, A. W. ACu3Ti4O12 and ACu3Ru4O12 perovskites: high dielectric constants and valence degeneracy. Solid State Sci. 4, 347-351 (2002)

16. Su, J. et al. Assembling ultrasmall copper-doped ruthenium oxide nanocrystals into hollow porous polyhedra: highly robust electrocatalysts for oxygen evolution in acidic media. Adv. Mater. 30, 1801351 (2018).

17. Shang, C. Y. et al. Electron correlations engineer catalytic activity of pyrochlore iridates for acidic water oxidation. Adv. Mater. 31, 1805104 (2019).

18. Rossmeisl, J., Qu, Z.-W., Zhu, H., Kroes, G.-J. \& Nørskov, J. K. Electrolysis of water on oxide surfaces. J. Electroanal. Chem. 607, 83-89 (2007). 
19. Man, I. C. et al. Universality in oxygen evolution electrocatalysis on oxide surfaces. ChemCatChem 3, 1159-1165 (2011)

20. Montoya, J. H., Doyle, A. D., Nørskov, J. K. \& Vojvodic, A. Trends in adsorption of electrocatalytic water splitting intermediates on cubic $\mathrm{ABO} 3$ oxides. Phys. Chem. Chem. Phys. 20, 3813-3818 (2018).

21. Jacobs, R., Hwang, J., Shao-Horn, Y. \& Morgan, D. Assessing correlations of perovskite catalytic performance with electronic structure descriptors. Chem. Mater. 31, 785-797 (2019).

22. Dickens, C. F., Montoya, J. H., Kulkarni, A. R., Bajdich, M. \& Nørskov, J. K. An electronic structure descriptor for oxygen reactivity at metal and metaloxide surfaces. Surf. Sci. 681, 122-129 (2019).

23. Stamenkovic, V. et al. Changing the activity of electrocatalysts for oxygen reduction by tuning the surface electronic structure. Angew. Chem. Int. Ed. 45, 2897-2901 (2006).

24. Ling, C., Shi, L., Ouyang, Y., Zeng, X. C. \& Wang, J. Nanosheet supported single-metal atom bifunctional catalyst for overall water splitting. Nano Lett. 17, 5133-5139 (2017).

25. Petrykin, V. et al. $\mathrm{Zn}$-doped $\mathrm{RuO} 2$ electrocatalyts for selective oxygen evolution: relationship between local structure and electrocatalytic behavior in chloride containing media. Chem. Mater. 23, 200-207 (2011).

26. Bolzan, A. A., Fong, C., Kennedy, B. J. \& Howard, C. J. Structural studies of rutile-type metal dioxides. Acta Cryst. B 53, 373-380 (1997).

27. Grimaud, A. et al. Double perovskites as a family of highly active catalysts for oxygen evolution in alkaline solution. Nat. Commun. 4, 2439 (2013).

28. Suntivich, J. et al. Estimating hybridization of transition metal and oxygen states in perovskites from O K-edge X-ray absorption spectroscopy. J. Phys Chem. C. 118, 1856-1863 (2014)

29. Mizumaki, M. et al. Oxygen hole state in A-site ordered perovskite $\mathrm{ACu} 3 \mathrm{Ru} 4 \mathrm{O} 12(\mathrm{~A}=\mathrm{Na}, \mathrm{Ca}$, and $\mathrm{La})$ probed by resonant $\mathrm{X}$-ray emission spectroscopy. J. Phys. Soc. Jpn. 82, 024709 (2013).

30. Xin, Y., Zhou, H. D., Cheng, J. G., Zhou, J. S. \& Goodenough, J. B. Study of atomic structure and electronic structure of an AA'3B4O12 double-perovskite $\mathrm{CaCu} 3 \mathrm{Ir} 4 \mathrm{O} 12$ using STEM imaging and EELS techniques. Ultramicroscopy 127, 94-99 (2013).

31. Crocombette, J. P., Pollak, M., Jollet, F., Thromat, N. \& Gautier-Soyer, M. Xray-absorption spectroscopy at the Fe L2,3 threshold in iron oxides. Phys. Rev. B 52, 3143 (1995).

32. Nørskov, J. K. et al. Origin of the overpotential for oxygen reduction at a fuelcell cathode. J. Phys. Chem. B. 108, 17886 (2004).

33. Rossmeisl, J. et al. Electrolysis of water on (oxidized) metal surfaces. Chem. Phys. 319, 178 (2005).

34. Xu, Z., Rossmeisl, J. \& Kitchin, J. R. A linear response DFT + U study of trends in the oxygen evolution activity of transition metal rutile dioxides. $J$ Phys. Chem. C. 119, 4827-4833 (2015).

35. Yang, $\mathrm{K}$. et al. Ultrasmall $\mathrm{Ru} / \mathrm{Cu}$-doped $\mathrm{RuO} 2$ complex embedded in amorphous carbon skeleton as highly active bifunctional electrocatalysts for overall water splitting. Small 14, 1803009 (2018).

36. Spöri, C., Kwan, J. T. H., Bonakdarpour, A., Wilkinson, D. P. \& Strasser, P. The stability challenges of oxygen evolving catalysts: towards a common fundamental understanding and mitigation of catalyst degradation. Angew. Chem. Int. Ed. 56, 5994-6021 (2017).
37. Grimaud, A. et al. Activating lattice oxygen redox reactions in metal oxides to catalyse oxygen evolution. Nat. Chem. 9, 2695 (2017).

38. Bockris, J. O. \& Otagawa, T. The electrocatalysis of oxygen evolution on perovskites. J. Electrochem. Soc. 131, 290 (1984).

39. Da Silva, L. M., De Faria, L. A. \& Boodts, J. F. C. Determination of the morphology factor of oxide layers. Electrochim. Acta 47, 395-403 (2001).

\section{Acknowledgements}

This work was financially supported by the National Science Foundation of China (Grant Nos. U1732149 and 21773124), the Fok Ying Tung Education Foundation (151008), and the Fundamental Research Funds for the Central Universities (63196010). We also thank the support from the National Super-Computing Center at Tianjin.

\section{Author contributions}

S.Z. and Z.H. designed the studies. X.M. synthesized the materials and studied their electrochemical properties. L.Z. and Z.H. carried out DFT calculations. L.W. assisted X.M. with the materials synthesis. S.Z., X.M., Z.H. and S.L. performed data analysis and wrote the paper. All authors discussed the results and commented on the manuscript.

\section{Additional information}

Supplementary Information accompanies this paper at https://doi.org/10.1038/s41467019-11789-3.

Competing interests: The authors declare no competing interests.

Reprints and permission information is available online at http://npg.nature.com/ reprintsandpermissions/

Peer review information: Nature Communications would like to thank Patricia Kooyman and other, anonymous, reviewers for their contributions to the peer review of this work.

Publisher's note: Springer Nature remains neutral with regard to jurisdictional claims in published maps and institutional affiliations.

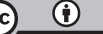

Open Access This article is licensed under a Creative Commons Attribution 4.0 International License, which permits use, sharing, adaptation, distribution and reproduction in any medium or format, as long as you give appropriate credit to the original author(s) and the source, provide a link to the Creative Commons license, and indicate if changes were made. The images or other third party material in this article are included in the article's Creative Commons license, unless indicated otherwise in a credit line to the material. If material is not included in the article's Creative Commons license and your intended use is not permitted by statutory regulation or exceeds the permitted use, you will need to obtain permission directly from the copyright holder. To view a copy of this license, visit http://creativecommons.org/ licenses/by/4.0/.

(C) The Author(s) 2019 